\title{
New 3-(2-pyridyl)-1,2,4-triazole derivatives and their palladium (II) complexes
}

Borys V. Zakharchenko, Dmytro M. Khomenko, Roman O. Doroschuk, Rostislav D. Lampeka

Department of Chemistry, Taras Shevchenko National University of Kyiv, Volodymyrska Street,

\author{
64/13, Kyiv 01601, Ukraine
}

dkhomenko@ukr.net

Keywords: palladium, triazole, coordination compound, NMR-spectroscopy

The article is devoted to investigation of coordination compounds of palladium (II) with 3-(2pyridyl)-1,2,4-triazole derivatives containing amino groups. We syntesized 4 ligands and 4 new coordination compounds. An interesting after removing of BOC-protection, $\mathrm{NH}_{2}$-group is still uncoordinated. In ${ }^{1} \mathrm{H}$ NMR spectra of complexes was a significant shift of the ortho-pyridine proton in a low-field area, which prove proposed structure. This may be due to its closeness to the lone electron pair of the nitrogen cycle of the second triazole ligand.

\section{Introduction}

Heterocyclic ligands play an important role in the development of coordination chemistry. Amongst available five-membered ring systems, triazoles represent an interesting class of compounds due to the presence of three nitrogens [1-3]. 1,2,4-Triazole derivatives show diverse pharmacological activities and have been examined as antitumor [4], antibacterial [5], antifungal [6] and antiviral agents [7].

Metal complexes containing triazole may also show biological activity, providing an impetus for the investigation of their coordination chemistry [8-10].

Complexes of 3-(2-pyridyl)-1,2,4triazoles typically have high stability, owing to the mutual combination of $\sigma$-donor and $\pi$ acceptor properties. If to compare electronic properties of 3-(2-pyridile)-1,2,4-triazolyl moiety with such wide used ligand as 2,2 - bypyridine, the first one is stronger $\sigma$-donor and weaker $\pi$-acceptor [11]. Also it should be noted that deprotonation of triazole ring arranges triazole containing ligands to act as a charged bidentate, or even tridentate ligands with simultaneous enhancing of complex stability.

Substantial amount of research has been dedicated to the study of noble metal complexes which incorporate derivatives of 1,2,4-triazole. This is due to their interesting photophysical and photochemical properties. Another possible use of these complexes is as catalysts in different chemical reactions. For example, palladium complexes can be used in crosscoupling reactions in preparative organic chemistry, as well as in obtaining of materials with luminescent properties [1-3].

\section{Results and discussion}

The synthesis of ligands $\mathbf{3}$ are based on acylation of $\mathbf{2}$ by iminoester $\mathbf{1}$ with 


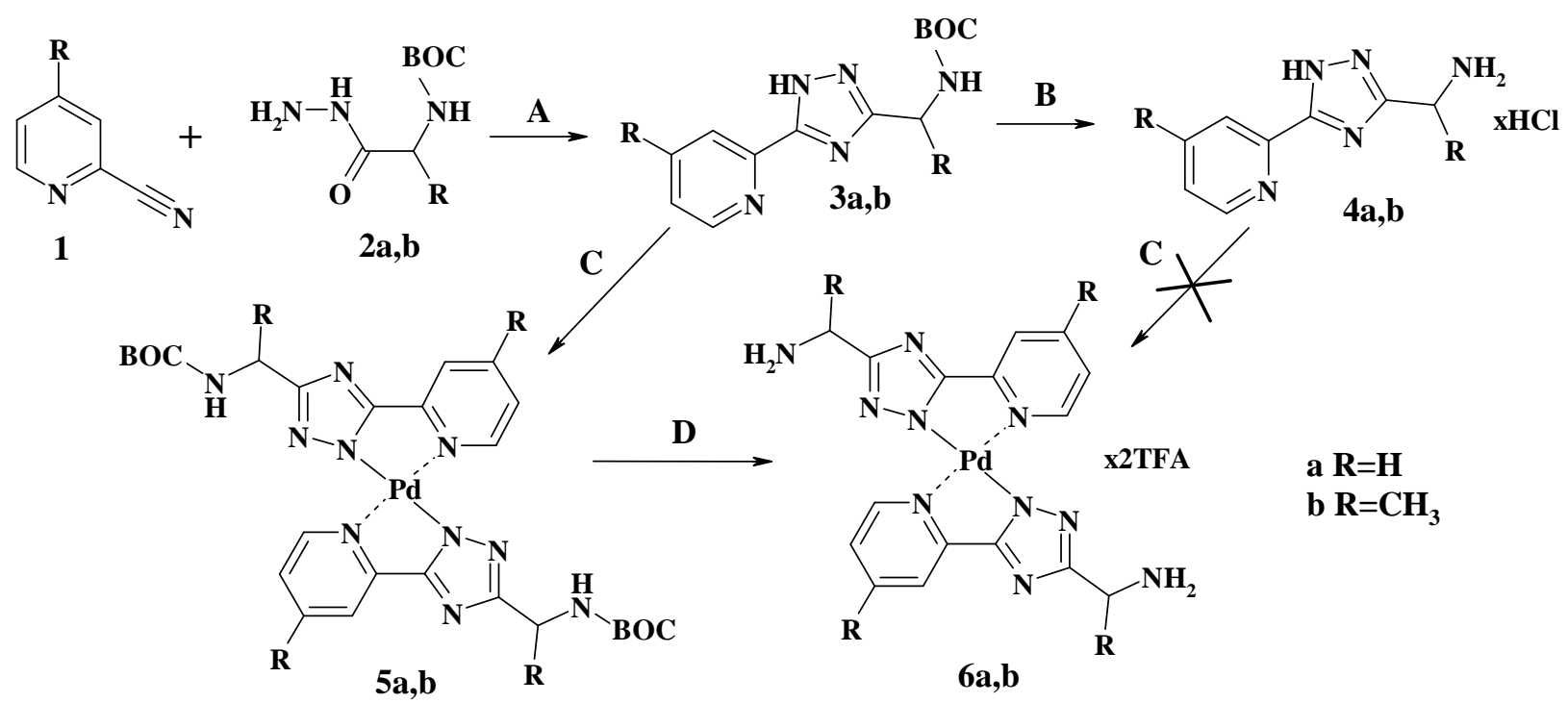

Scheme 1. Reagents and conditions: (A) MeONa, reflux, 10h; (B) $\mathrm{HCl}$, i-PrOH, reflux, 24h;

(C) $\mathrm{PdCl}_{2} \mathrm{x} 2 \mathrm{CH}_{3} \mathrm{CN}, \mathrm{Et}_{3} \mathrm{~N}, \mathrm{CH}_{3} \mathrm{CN}$; (D) TFA, DCM, reflux, $2 \mathrm{~h}$.

subsequent cyclization of the resulting amidrazones into 1,2,4-triazoles (Scheme 1). Deprotection of $\mathbf{3}$ in acidic conditions leads to formation of amines 4 . The attempts to obtain 6 directly from ligands were unsuccessful, because of palladium reduction. Therefore we have synthesized palladium complexes $\mathbf{5}$ using BOC protected amines. Deprotection of $\mathbf{5}$ with TFA leads to obtaining of title compounds.

The absence of a ${ }^{1} \mathrm{H}$ NMR signal for the proton connected to the triazol ring, indicates the deprotonated form of ligands in $\mathbf{5}$ and $\mathbf{6}$. It is noteworthy that the chemical shift of the orthoPy proton in 5a and 5b are 9.54 and 9.35 ppm respectively, i.e. this proton becomes less shielded compared to the free ligand $\left(\Delta \delta_{5 \mathrm{a}}=+0.91 \mathrm{ppm}, \Delta \delta_{5 \mathrm{~b}}=+0.71\right)$.

Deprotection of $\mathbf{5}$ with TFA leads to formation of trifluoroacetates of title compounds 6. TFA was used for this purpose instead of $\mathrm{HCl}$, because reaction with latter results in $\mathrm{PdCl}_{2}$ formation. Changes in ${ }^{1} \mathrm{H}$ NMR-spectra of $\mathbf{6}$ comparing to free ligands is of the same character as in $\mathbf{5} . \Delta \delta$ For ortho-Py proton in $6 \mathbf{a}$ and $\mathbf{6 b}$ is +0.94 and $+0.85 \mathrm{ppm}$ respectively. These could be realized in the structure proposed for 5 and 6 (Fig.1), where the ortho-Py proton is situated in a deshielded

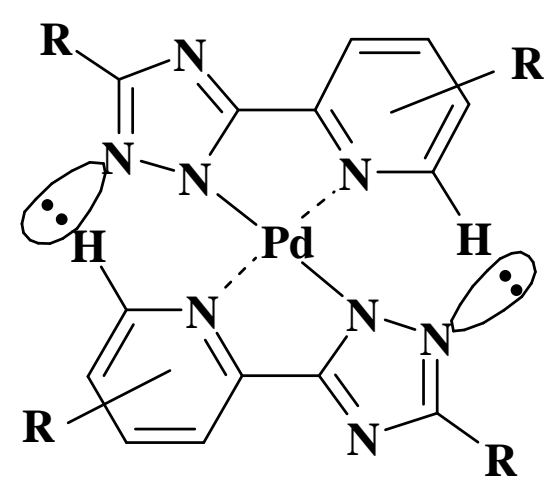

Fig.1. Schematic illustration of $\mathbf{5}$ and $\mathbf{6}$ structure.

region formed by a triazole ring of an opposite ligand molecule, which is an accordance with previously obtained compounds [12].

\section{Conclusion}

This article describes synthesis and characterization of four novel palladium (II) complex containing 3-(2-pyridyl)-1,2,4-triazole moiety. Two of them were obtained by 
deprotection of amino groups in corresponding complexes. The structure of title compounds was proved by means of ${ }^{1} \mathrm{H}$ NMR spectroscopy.

\section{Experimental part}

Elemental analyses were carried out at Perkin-Elmer"2400"CHN Analyzer. NMR spectra in DMSO- $\mathrm{d}_{6}$ solution were recorded on a Varian"400"spectrometer at room temperature.

General procedure A (3a,b): $10 \mathrm{ml}$ of sodium methoxide methanolic solution (35 wt\%) was added to solution of $1(0.05 \mathrm{~mol})$ in $20 \mathrm{ml}$ of methanol and stirred at room temperature for 1 hour. Then $\mathbf{2}$ was added to obtained iminoester solution and refluxed for 10 hours. Obtained mixture was cooled to room temperature and solvent removed in vacuo. The resulting suspension was diluted with water and acidified with $2 \mathrm{ml}$ of acetic acid to obtain a white solid. The crystals were separated via filtration, dried and recrystalized from toluene.

3-(2-pyridyl)-5-Boc-methylamino-1,2,4-triazole (3a): $6.26 \mathrm{~g},(62.0 \%)$, white crystals. ${ }^{1} \mathrm{H}$ NMR (DMSO-d $\left.{ }^{6}, 400 \mathrm{MHz}\right)$ : dH(ppm) 14.72-14.50 (br s, $1 \mathrm{H}), 8.62(\mathrm{~d}, 1 \mathrm{H}), 8.11(\mathrm{~m}, 1 \mathrm{H}), 7.97$ (m, $1 \mathrm{H}), 7.47(\mathrm{~d}, 1 \mathrm{H}), 7.15$ (br s, $1 \mathrm{H}), 4.26$ (s, $2 \mathrm{H}), 1.39$ (s, $9 \mathrm{H}$ ). Anal. calcd. for $\mathrm{C}_{13} \mathrm{H}_{17} \mathrm{~N}_{5} \mathrm{O}_{2}$, \%: C,56.71; H,6.22; N,25.44. Found: C,56.98; $\mathrm{H}, 6.15 ; \mathrm{N}, 25.88$.

\section{3-(2-pyridyl-4-methyl)-5-Boc-isopropylamine-}

1,2,4-triazole (3b): 6.88 g, (69\%), white crystals. ${ }^{1} \mathrm{H}$ NMR (DMSO-d ${ }^{6}, 400 \mathrm{MHz}$ ): dH(ppm) 14.81-14.66 (br s,1 H), 8.69 (d, 1 H), $8.06(\mathrm{~d}, 1 \mathrm{H}), 7.52(\mathrm{~s}, 1 \mathrm{H}), 7.09$ (br s, $1 \mathrm{H})$, 4.29 (s, 1 H), 2.35 (s, 3 H) 1.42 (d, 3 H), 1.34 (s, $9 \mathrm{H})$. Anal. calcd. for $\mathrm{C}_{15} \mathrm{H}_{21} \mathrm{~N}_{5} \mathrm{O}_{2}, \%$ : C,59.39;
$\mathrm{H}, 6.98 ; \quad \mathrm{N}, 23.09$. Found: C,59.52; H,6.58; $\mathrm{N}, 23.44$.

General procedure $B(\mathbf{4 a}, \mathbf{b}): 0.9 \mathrm{ml}$ of hydrochloric acid $(3.00 \mathrm{M})$ was added to solution of $\mathbf{3}(0.03 \mathrm{~mol})$ in $50 \mathrm{ml}$ of isopropanole and refluxed for $24 \mathrm{~h}$. Solvent was removed under vacuo to obtain a white crystals of 4 .

\section{3-(2-pyridyl)-5-methylamino-1,2,4-triazole}

(4a): $5.01 \mathrm{~g},(92.0 \%)$, white crystals. ${ }^{1} \mathrm{H}$ NMR (DMSO-d $\left.{ }^{6}, 400 \mathrm{MHz}\right)$ : dH(ppm) 15.10-14.85 (br s, $1 \mathrm{H}), 8.78$ (br s, $3 \mathrm{H}), 8.71$ (d, $1 \mathrm{H}), 8.06$ 7.97 (m, 2 H), 7.54 (d, 1 H), 4.13 (s, 2 H). Anal. calcd. for $\mathrm{C}_{8} \mathrm{H}_{10} \mathrm{ClN}_{5} \mathrm{O}_{2}, \%$ : $\mathrm{C}, 45.40 ; \mathrm{H}, 4.76$; $\mathrm{N}, 33.09$. Found: C,45.88; H,4.62; N,33.23.

\section{3-(2-pyridyl-4-methyl)-5-isopropylamine-1,2,4-} triazole (4b): 4,93 g, (89\%), white crystals. ${ }^{1} \mathrm{H}$ NMR (DMSO-d $\left.{ }^{6}, 400 \mathrm{MHz}\right)$ dH(ppm) 14.85 $14.61($ br s, $1 \mathrm{H}), 8.79$ (s, $3 \mathrm{H}), 8.66(\mathrm{~s}, 1 \mathrm{H})$, 8.02-7.92 (m, $2 \mathrm{H}), 4.16$ (s, $1 \mathrm{H}), 2.53(\mathrm{~m}, 3 \mathrm{H})$, 1.49 (d, $3 \mathrm{H})$. Anal. calcd. for $\mathrm{C}_{10} \mathrm{H}_{14} \mathrm{ClN}_{5}$, \%: C,50.11; H,5.89; N,29.22. Found: C,50.48; $\mathrm{H}, 5.75 ; \mathrm{N}, 29.53$.

General procedure $\boldsymbol{C}(\mathbf{5 a}, \mathbf{b}): \mathrm{PdCl}_{2} \times\left(\mathrm{CH}_{3} \mathrm{CN}\right)_{2}$ $(0.26 \mathrm{~g}, 1 \mathrm{mmol})$ in hot acetonitrile $(20 \mathrm{~mL})$ was added to solution of $\mathbf{3}(2 \mathrm{mmol})$ and $\mathrm{Et}_{3} \mathrm{~N}(0.29$ $\mathrm{ml}, 2 \mathrm{mmol})$ in acetonitrile $(20 \mathrm{ml})$. Precipitated yellow crystals were collected by filtration, washed with acetonitrile and dried in air.

5a: ${ }^{1} \mathrm{H}$ NMR (DMSO-d $\left.{ }^{6}, 400 \mathrm{MHz}\right)$ : $\mathrm{dH}(\mathrm{ppm})$ $9.54(\mathrm{~d}, 2 \mathrm{H}), 8.54$ (m, $2 \mathrm{H}), 7.96$ (m, $2 \mathrm{H}), 7.58$ (d, 2 H), 4.69 (s, 4 H), 1.49 (s, 18 H). Anal. calcd. for $\mathrm{C}_{26} \mathrm{H}_{32} \mathrm{~N}_{10} \mathrm{O}_{4} \mathrm{Pd}$, \%: C,53.44; $\mathrm{H}, 4.28$; N,22.44. Found: C,53.82; H,4.54; N,22.19. 5b: ${ }^{1} \mathrm{H}$ NMR (DMSO-d $\left.\mathrm{d}^{6}, 400 \mathrm{MHz}\right): \mathrm{dH}(\mathrm{ppm})$ 9.35 (s, $2 \mathrm{H}), 7.96-7.58$ (m, $4 \mathrm{H}), 4.19$ (s, $2 \mathrm{H})$, 
$2.61(\mathrm{~d}, 6 \mathrm{H}), 1.57$ (s, $6 \mathrm{H}), 1.42$ (s, $18 \mathrm{H})$. Anal. calcd. For $\mathrm{C}_{30} \mathrm{H}_{40} \mathrm{~N}_{10} \mathrm{O}_{4} \mathrm{Pd}, \%$ : C,50.67; H, 5.68; N,19.71. Found: C,50.82; H,5.59; N,19.33.

General procedure $D(6 \mathbf{6}, \mathbf{b})$. Solution of 1 mmol TFA in DCM was added to suspension of $5(0,5 \mathrm{mmol})$ in $20 \mathrm{ml}$ of DCM and then refluxed for $2 \mathrm{~h}$. The mixture was then cooled to room temperature and the solvent was removed to obtain light yellow crystals of $\mathbf{6}$.

6a: ${ }^{1} \mathrm{H}$ NMR (DMSO-d $\left.{ }^{6}, 400 \mathrm{MHz}\right): \mathrm{dH}(\mathrm{ppm})$ 9.71 (d, 2 H), 8.56 (m, 2 H), 7.97 (m, 2 H), 7.61 $(\mathrm{d}, 2 \mathrm{H}), 4.72(\mathrm{~s}, 4 \mathrm{H})$. Anal. calcd. for $\mathrm{C}_{20} \mathrm{H}_{18} \mathrm{~F}_{6} \mathrm{~N}_{10} \mathrm{O}_{4} \mathrm{Pd}$, \%: C,35.18; H,2.66; N,20.51. Found: C,34.98; H,2.54; N,20.69.

6b: ${ }^{1} \mathrm{H}$ NMR (DMSO-d 6 , $\left.400 \mathrm{MHz}\right)$ : dH(ppm) $9.64(\mathrm{~d}, 2 \mathrm{H}), 8.58$ (s, $4 \mathrm{H}), 7.86(\mathrm{~m}, 2 \mathrm{H}), 7.52$ (d, 2 H), 4.63 (s, 2 H), 2.57 (s, $6 \mathrm{H}), 1.67$ (d, 6 H). Anal. calcd. for $\mathrm{C}_{20} \mathrm{H}_{25} \mathrm{~N}_{10} \mathrm{Pd}, \%$ : C,39.01; H, 3.55; N,18.96. Found: C,38.72; H,3.84; $\mathrm{N}, 18.55$.

\section{References}

[1] Klingele M.H., Brooker S., Coord. Chem. Rev. 2003, 241,119-132. doi: 10.1016/S0010-8545(03)000493.

[2] Haasnoot J.G., Coord. Chem. Rev. 2000, 200202, 131-185. doi:10.1016/S0010-8545(00)00266-6.

[3] Aromi G., Barrios L.A., Roubeau O., Gamez P., Coord. Chem. Rev. 2011, 255, 485-546. doi: 10.1016/j.ccr.2010.10.038.

[4] Morales-Morales D., Jensen C.M. (Eds). The Chemistry of Pincer Compounds, Elsevier, The Netherlands (2007).

[5] Banachiewicz B. M.; Chodkowska A.; Wójtowicz E. J.; Eur. J. Med. Chem. 2004, 39, 873-877. doi:10.1016/j.ejmech.2004.07.002.

[6] Zhao, Q. J.; Song, Y.; Gang Hu, H.; Chong Yu, S.; Ye Wu, Q., Chin. Chem. Lett. 2007, 18, 670-672. doi:10.1016/j.cclet.2007.04.019
[7] Lebouvier, N.; Pagniez, F.; Duflos, M.; Pape, P. L.; Min Na, Y.; Bauta, G. L.; Borgnea, M. L., Bioorg. Med. Chem. Lett. 2007, 17, 3686-3689. doi: 10.1016/j.bmcl.2007.04.038.

[8] Kus, C.; Kılcıgil, G. A.; Ozbey, S.; Kaynak, F. B.; Kaya, M.; Coban, T.; Can-Eke, B.,Bioorg. Med.Chem. 2008, 16, 4294-4303. doi: 10.1016/j.bmc.2008.02.077.

[9] Albrecht M., van Koten G.. Angew. Chem. Int. Ed. 2001, 40, 3750. doi: 10.1002/15213773(20011015)40:20<3750::AID-ANIE3750>3.0.CO;26.

[10] Boom van der M.E., Misltein D., Chem. Rev. 2003, 103, 1759. doi: 10.1021/cr960118r.

[11] Van Diemen J.H., Haasnoot J.G., Reedijk J., Inorg. Chem. 1991, 30(21), 4038-4043. doi: 10.1021/ic00021a013

[12] Zakharchenko BV, Khomenko DM, Doroschuk RO, Lampeka RD, Rep. of the NAS of Ukraine 2015, 5, 125-129

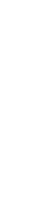

